\title{
VoiceYourView: anytime, anyplace, anywhere user participation
}

\author{
Andree Woodcock , Katerina Frankova and Laurence Garton \\ Centre of Excellence in Product and Automotive Design, Department of Industrial Design, Coventry School of Art \\ and Design Coventry University, Coventry, UK.
}

\begin{abstract}
Citizens are increasingly called upon to comment on issues that directly concern them. However, such consultations may be tokenistic [1] as they occur with limited respondents, or may be at a time, or in a format which is inconvenient to the user. To encourage wider participation, the VoiceYourView project (vYv) has developed a system allowing people to make comments in a manner, time and place convenient to them. A real world trial of the prototype system was conducted at Coventry University campus to explore issues related to the system's usability and usage, as a means of enabling campus users to comment on their environment. Members of the university population were invited to comment on the university estate using one of five technologies (e-mail, online form, iPhone app, SMS message, or electronic kiosk). Although the immediate application area in this case was the design of public spaces, the approach can be transferred to other domains and thus provide a new way of gathering user information. Submitted comments were automatically analysed in terms of theme, sentiment, location and actionability and displayed online in a 2D visualisation. It is argued that that online data collection (crowd sourcing and skimming social networks) may provide a rich source of information for future ergonomists.
\end{abstract}

Keywords: User engagement, public spaces, user consultation

\section{Introduction}

The 3 year research council funded VoiceYourView project is looking at ways people's knowledge of public spaces can be captured in order to create safer, more inclusive spaces [2]. It is believed that the users of a public space know it best, but at present only a small proportion of their views are taken into account during public consultations before construction and through post-occupancy evaluation surveys. All users have opinions about the spaces in which they live and work, or see things which worry them as they move through spaces. While they may discuss such issues with their friends and colleagues, this feedback may never reach the designers or the local authorities.

The VoiceYourView project aims to develop ways to collect people's views as they walk through spaces, then structure and store these in an online repository where they can be seen by other users, such as local community groups, local authorities, etc. By so doing, it is believed that the use of system like VoiceYourView will lead to public spaces that are more attuned to the needs of their users.
Coventry University campus was selected as one of the suitable trial sites due to its current regeneration activities. The university is planning to invest $£ 160 \mathrm{~m}$ in the redevelopment of the campus over the next ten years [3]. As part of these developments, a new multi-storey staff car park and a student 'Hub' have been opened and a new Computing and Engineering building is currently under construction. However, the Estates Department and the University as a whole had not performed widespread consultation with campus users about what the campus should look like.

The idea of using digital technologies to enhance civic engagement - or, in other words, heighten people's sense of responsibility to their community, is not new. In 2003, Fogg proposed that technologies can be used to influence people and encourage behaviour changes [4]. His model contained three key elements: motivation, ability (simplicity) and triggers - which means the design should connect with people emotionally, enable users to advance their abilities and attract them to move toward target behaviours.

Evidently, governments are keen to use digital technologies to reach wider audiences. Recently, the 
UK government launched the Spending Challenge website to give people opportunities to shape the government spending plan. It was reported that more than 100,000 suggestions were collected and more than 44,000 ideas came from the public [5]. Moreover, the US government uses various digital technologies to facilitate open, transparent and cost-effective interactions between governments and citizens, e.g. the Open Government Initiative.

Currently, several smart phone applications and web tools, e.g. SeeClickFix (www.seeclickfix.com) and CitySourced (www.citysourced.com), allow people to capture images and report their concerns about their neighbourhoods to local governments. Although smart phones and web technologies give new means to access governmental data, complain and give feedback to governments, they exclude large populations that cannot and/or do not want to use them. For instance, recent research showed that there are still 12.5 million people in the UK who are not active users of the internet and a large population of the group are people over the age of 55 [6].

The vYv system will not achieve the best results unless it appeals to everyone and all groups of people can contribute equally. To ensure the inclusive approach, the technological development and user research were carried out in parallel. Design research was conducted to identify an appropriate design strategy for key aspects [7].

The aim of the trial conducted at Coventry University campus was to give its users an opportunity to comment on the physical aspects of the campus itself. The information gathered was then passed on to the university's Estates department who would use it to act upon as well as inform their future development plans

\section{The Coventry study}

The aim of the vYv system trial was to give the university staff, students and visitors an opportunity to comment on the physical aspects of the campus. The scope of the trial was left relatively broad in order to give the campus users the freedom to raise whatever they felt was important. Thus, they could give their opinion on the current state of the campus, the developments taking place, ideas for future developments, or just raise maintenance issues. If considered feasible by Estates, these comments would be taken into consideration when putting together future plans for the campus. Additionally all comments were forwarded on to Estates to inform their development plans.

\subsection{Aims and objectives}

The individual objectives were 1) to develop a variety of technologies that could be used by public space users in communicating their needs and aspirations for public spaces; 2) to implement these technologies and raise awareness of the VoiceYourView project at Coventry University; 3) to use these technologies to engage staff, students and visitors of Coventry University in a consultation about the university campus; 4) to measure the effectiveness of the different technologies in terms of quality of data, popularity and other factors and 5) to engage staff, students and visitors in a dialogue about the current state of the campus.

The following hypotheses were also tested in terms of the technologies used:

- There will be significant differences in the quality and quantity of comments from different sources (in particular, between static and mobile devices).

- Participants using the iPhone application will comment more on their immediate location as opposed to remote locations

\subsection{Methodology}

The trial ran for 12 weeks in the autumn term of 2010 . Its start was linked to the beginning of the academic year.

\subsubsection{Promotion of trial}

A range of publicity materials was developed to engage staff, students and visitors around the campus area. This included flyers in shops and locations favoured by staff and students, e-mails, posters on notice boards and on the university intranet, adverts on flat screens in the main university buildings, on the home page of the e-learning system and in the fresher's handbook. The trial was also promoted face-toface at the fresher's fair.

\subsubsection{Data collection methods}

Promotional materials urged campus users to 'voice their view' and submit a comment about what they thought of the public spaces of the campus. An emphasis was placed on physical aspects, such as green spaces, pavements, squares and car parks, in- 
stead of building interiors. Compliments, complaints as well as general comments were welcome.

VoiceYourView users could select from one of 5 methods to submit their comments about the campus. They could use whichever of the methods they found the most convenient to them. There was no limit on how many comments could be submitted per person. The methods included e-mail (with no restriction on text length), text message (of up to 160 characters), online structured form, an iPhone application and 3 purposely designed electronic kiosks. These presented a map and a structured form, similar to the online form. The kiosks were placed into three locations around the campus, including the library, Students' Union and one building frequented mostly by staff and visitors.

\subsubsection{Pre-trial usability testing}

Prior to the launch of the trial, appropriate usability studies were carried out. A convenience sample of 12 representative end-users, drawn from the university population, 'voiced their view' about the campus using each of the input methods. The testing revealed a number of problems.

Kiosk: Users did not realize this featured a touch screen. The map used to pinpoint locations was too small. To resolve these, a 'touch screen to start' notice was placed on the monitor and instructions added to the map to draw attention to zoom in/out functions.

Online form: The font adopted was too small and the pop-up instructions were of the same colour as the background panel. These were rectified prior to the trial

iPhone application: Text field for making the comment was not obvious. This was clarified by adding a usage message. Unfortunately the usability study had not identified the fact that the app should have specified that it was to be used for comments about the Coventry University campus only. Throughout the trial, the app was often downloaded by people from all over the world, who wished to 'voice their view'.

Text/SMS: For the text message to be sent to the correct database, users had to start their message with 'vyv' before sending it to a 5-digit number. The pretrial study showed that users often did not understand the instruction "use the prefix "vyv"" in the promotion materials, resulting in them not sending the message correctly. Due to promotion materials being already printed, this could not be rectified before the trial and may have resulted in an under use, or underrecording of usage of this technology
E-mail: Users were not sure whether the subject line of the e-mail needed to be completed.

Despite having conducted pre-trial technology and usability studies and making necessary adjustments, practical and technological problems occurred during the trial. These will be explored in more detail in the Results and Lessons learnt sections.

\subsection{Results}

The comments were automatically entered into a database. Comments which were related to willful misuse and technological error were removed. Entries which related to more than one issue were split into their appropriate parts. Therefore, one comment could have been split into two or three, if it covered more than one issue. This applied mostly to comments submitted by e-mail, whereas online forms and kiosks tended to generate comments with one main theme only. The material was independently scored by three raters in terms of theme (or category of the response; e.g. public spaces/green spaces; lighting; university buildings), actionability (meaning the level of detail provided in the comment) and sentiment (compliment, complaint or general comment). Where disagreements occurred amongst the raters, these were discussed until consensus was reached. This was later compared with the automatic analysis undertaken by the system.

\subsubsection{By category/theme}

130 comments were submitted to the system. These were coded into 22 categories (or themes) which related to artefacts in the environment (such as lighting or pavements) or issues such as safety and cleanliness (see Figure 1). The majority of categories had been preselected in discussion with the Estates department, although some were added during the analysis, e.g. 'computers' and 'library'. These were mentioned frequently by participants who used the kiosk located in the library. No distinction is made in Figure 1 concerning positive and negative comments.

Safety was mentioned most frequently (tagged 22 times). In this category comments could relate to lighting at night, crossing dangerous roads and the general maintenance of the campus, e.g. the condition of pavements. Below are three examples of safety related comments:

"There are lots of leaves on the steps that lead under and through James Starley [building] from Cox Street zebra crossing. These are especially slippery 
when wet. Would it be possible to have these more regularly swept up?"

"I think it would be safer to have a pedestrian bridge to cross Sky Blue Way [a very busy road], as I regularly see people crossing six lanes of traffic, which is very unsafe. This is because the only other way over [...] to the main campus is to either walk this route, or to go up to Cox Street."

"When lectures don't finish until $6 \mathrm{pm}$, I have to walk through the campus (usually from Armstrong Siddeley [building]) to get the bus station, and it is "pitch black". I have noticed that there is hardly any lighting throughout the campus and by the cathedral, I find this quite dangerous particularly when wet." I

\section{Frequency of comments per theme}

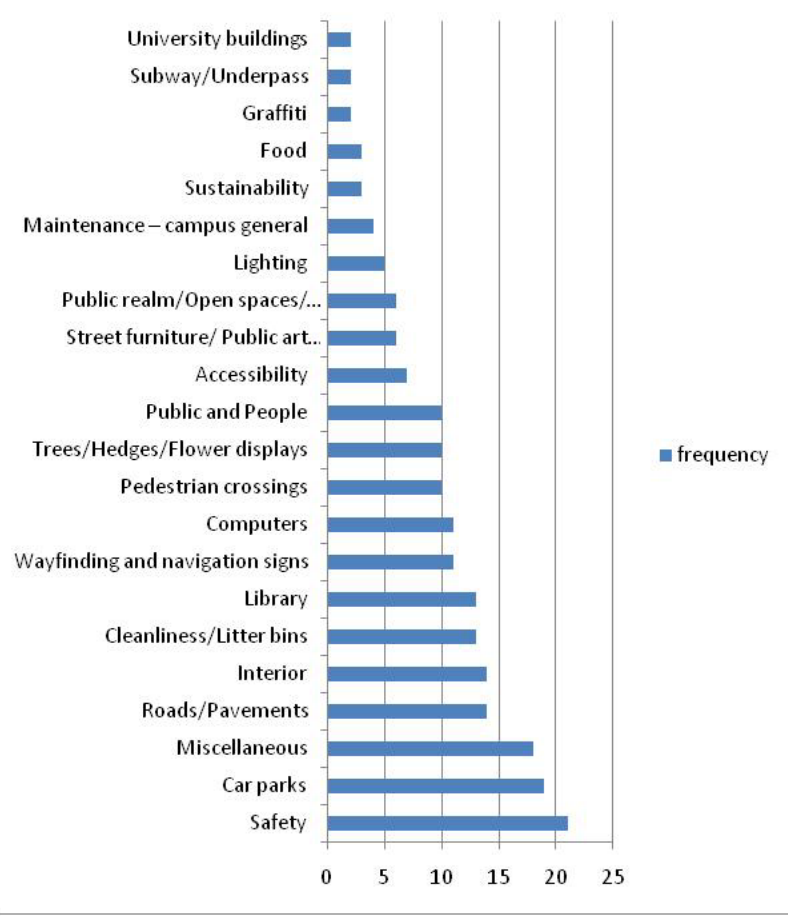

Figure 1: Comments against theme

'Car parks' was the second most tagged theme from the list, with total of 19 comments. A large proportion of these related to the issue of lack of student parking, with a few positive comments mentioning the new staff car park.

\footnotetext{
${ }^{1}$ As text appeared in the e-mail. Illustrating the need for a location aware NLP
}

\subsubsection{By sentiment}

The analysis of the themes shows safety was the most frequently tagged theme and that graffiti, subways/underpasses were the least commented on. However, to look further into this, the data was analysed against the sentiment of the comment given to discover which themes were commented on negatively and which were positively. Compliments were seen as positive, complaints as negative and general comments as neutral. This then identified which themes were of most concern to users of the university public realm. Figure 2 shows safety as being the largest concern/theme around the campus as it is the most tagged theme with a negative sentiment. The most positively tagged theme was trees/hedges/flower displays with a total of $6 \mathrm{com}$ ments. However a further five negative comments were also tagged with this theme.

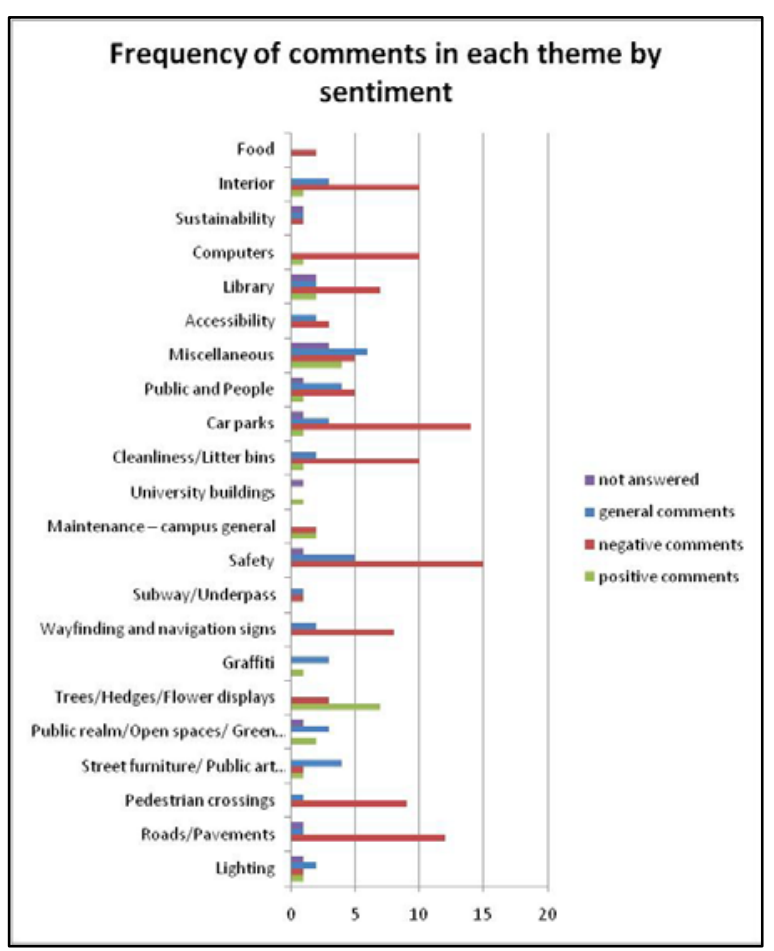

Figure 2: Comments rated in terms of sentiment

Although no firm conclusions can be drawn from the sentiment analysis, it appears that participants in general complained more than complimented, and that of the technologies available, more complaints were expressed on e-mail entries. Clearly detecting the sentiments expressed by participants is important if policy decisions are to be made based on the analy- 
sis. For a discussion of automatic sentiment analysis conducted in the project, please refer to [8].

\subsubsection{By actionability}

A three point scale was used to determine whether comments were actionable - related to the level of detail included in the comment. To be rated as actionable the comment had to include a clear description of a problem, its location and indicate how it might be solved. Overall, e-mail comments proved to be the most actionable. E-mail comments submitted to the vYv system tended to be much longer and descriptive than comments submitted through the other technologies. The kiosk provided the most 'non actionable' comments of all the technologies.

\subsubsection{By data entry method}

The kiosk was used the most, however it also generated the highest number of irrelevant comments (which did not relate to the physical aspects of the campus), as can be seen in Table 1. The high number of irrelevant comments would suggest that the kiosk was often used out of curiosity, when the user noticed it and thought he or she would give it a try. Unfortunately, in these cases the users did not necessarily have anything relevant to say, their comment was about something different to physical spaces, or involved willful misuse. A high number of 'irrelevant' comments was submitted to the kiosk located in the library, where these comments related to the low speed or small number of computers or library service. This would imply that users believed that the kiosk was there for them to submit comments about the library itself and not the campus as a whole.

Table 1: Use of different input mechanisms

\begin{tabular}{|c|c|c|}
\hline Input method & Description & $\begin{array}{c}\text { No. of } \\
\text { comments }\end{array}$ \\
\hline \multirow{5}{*}{ E-mail } & tech errors & 865 \\
\hline & willful misuse & 0 \\
\hline & irrelevant & 3 \\
\hline & relevant & 20 \\
\hline & total & 888 \\
\hline \multirow{5}{*}{ Online form } & tech errors & 15 \\
\hline & willful misuse & 0 \\
\hline & irrelevant & 6 \\
\hline & relevant & 35 \\
\hline & total & 56 \\
\hline \multirow{3}{*}{ Text message } & tech errors & 1 \\
\hline & willful misuse & 0 \\
\hline & irrelevant & 1 \\
\hline
\end{tabular}

\begin{tabular}{|c|c|c|}
\hline & relevant & 3 \\
\hline & total & 5 \\
\hline \multirow{5}{*}{ iPhone } & tech errors & 25 \\
\hline & willful misuse & 0 \\
\hline & irrelevant & 1 \\
\hline & relevant & 1 \\
\hline & total & 27 \\
\hline \multirow{5}{*}{ Kiosk } & tech errors & 87 \\
\hline & willful misuse & 12 \\
\hline & irrelevant & 31 \\
\hline & relevant & 29 \\
\hline & total & 159 \\
\hline \multicolumn{2}{|c|}{ Total relevant comments } & 130 \\
\hline \multicolumn{2}{|c|}{ Total trial comments in database } & 1364 \\
\hline
\end{tabular}

Only $48 \%$ of the comments submitted via kiosk were relevant. Online form was the second most frequently used method with a high relevance rate of $85 \%$ (Figure 3). E-mail, the third most frequently used method, included only three irrelevant comments, which means that $87 \%$ of comments were relevant. Finally, text message and iPhone app did not prove successful. This could be linked back to the two hypotheses outlined earlier. One of the assumptions was that iPhone users would comment more on their immediate locations as opposed to remote locations. This could be seen as true, as was the case of comments about quality of hotels etc, submitted from abroad by unintended users who had downloaded the app randomly, but used it for a different purpose than the actual vYv trial. However, for the purpose of this study, the iPhone app was in fact hardly used at all. In terms of quantity of comments obtained from the different sources, both text messages and iPhone had the lowest uptake. Only five valid text messages were received, as opposed to 56 valid online forms and 159 kiosk entries.

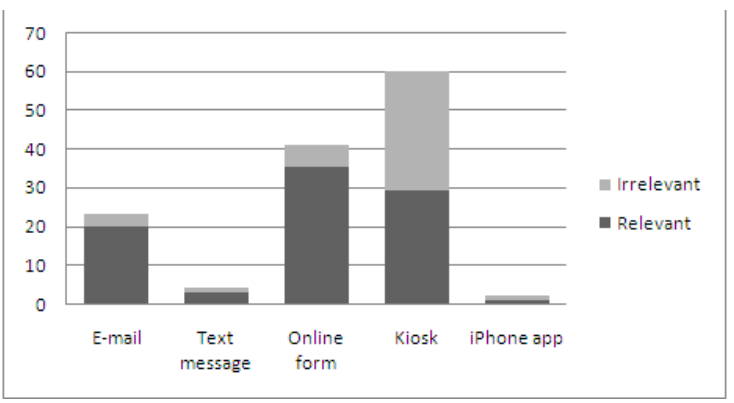

Figure 3: Number of relevant comments by technology 


\subsection{Conclusions}

In terms of the original hypotheses, there were too few responses to draw any conclusions. In this trial the static devices (online form, kiosks and e-mails) were the most frequently used, with e-mail providing the highest quality in terms of relevance and actionability. The iPhone app was not used sufficiently for any conclusions to be drawn from this. Its uptake may have been affected by the marketing of the app as well as its reliance on iPhone ownership within the campus user group. The inclusivity of technological solutions needs to be further considered.

\subsection{Discussion}

Since the trial was conducted the VoiceYourView team have conducted additional, more site specific trials with greater levels of participation, and are currently exploring how to create opportunities for more playful interactions. More details can be found on the project web site at http://www.voiceyourview.com/site/content home.p $\underline{\mathrm{hp}}$

\section{Lessons learnt}

Overall participation in the trial was not as high as was expected. This may be due to a number of reasons: the apathy of the university population, the unfocussed nature of the trial, lack of interest, lack of major problem areas within the campus, advertising not being targeted enough and not using new communication channels such as social networking sites, and confusion caused by the number of input channels which were available. More focused trials conducted as part of the overall project have produced higher response rates. A follow up survey with those who had not participated showed that many people were not aware of the trial and those who were could not think of what to comment on. When they were asked what communication channels should have been used, they specified ones that had actually been used, but which still failed to capture attention.

Inserting new technology into an existing technological infrastructure was more difficult than anticipated. Although we had the necessary levels of support across the university and had left three months for technical implementation, unexpected problems arose with firewalls, security, compatibility of machines with services in different buildings, and the instability of servers across the university. This necessitated daily checking of all equipment to ensure that it was working as expected.

In conclusion, the trial expected too much of the users because it required them to:

1. Notice the study

2. Be willing to take part

3. Be sufficiently energized by their surroundings to make a comment

4. Discover the most appropriate input mechanism

5. Enter their comment

It is therefore recommended that ergonomists and behavioural scientists who wish to use technology to capture the views of citizens as they engage in their everyday activities focus down on particular issues or localities, gain buy in from community champions who can encourage people to take part (or work with a group of users), reduce the number of ways in which people can submit information and use technology which is already familiar to the people - such as preferred social networking sites.

In this trial, the results of the analysis were given to the Estates department. An additional requirement of all studies which seek to engage the public in any form of consultation must be that the data is used to affect change, i.e. is used to inform policy, or in this case the design of public spaces. Evidence gathered in other parts of this research show that policy makers and planners find it hard to use data collected in public consultations, especially if that data is in a text format. In such cases a system such as VoiceYouView which can extract summary data from text entries may be useful.

\section{Acknowledgements}

VoiceYourView (vYv) is a cross disciplinary research project funded by the Engineering and Physical Science Research council's Digital Economy Programme, grant number EP/H007237/1. It is a collaboration between five leading universities in the UK: Lancaster, Brunel, Sheffield, Manchester and Coventry University.

\section{References}

[1] S. Arnstein, (1969) 'The ladder of citizen participation', Journal of the Institute of American Planners, 35 (4) 216 224 
[2] J. Whittle, W. Simm, M.A. Ferrario, K. Frankova, L. Garton, A. Woodcock, B. Nasa, J. Binner, A. Ariyatum, VoiceYourView: Collecting Real-time Feedback on the Design of Public Spaces. Proceedings Ubicomp 2010, Copenhagen, Denmark 2010 p41-50.

[3] Coventry University (2010) 'Campus' [online] available from

http://wwwm.coventry.ac.uk/university/campus/Pages/Ourca mpus.aspx [Accessed Oct 2010]

[4] B.J. Fogg (2003). Persuasive Technology: Using computer to change what we think and do. San Francisco: Morgan Kaufman Publishers ,2003

[5] HM Treasury (2010). Spending Review [Online] $\mathrm{http}: / / \mathrm{www} \cdot \mathrm{hm}$ treasury.gov.uk/spend_spendingchallenge.htm ,2010. Last accessed: 20/09/10

[6] Department for Business, Innovation and Skills, National Plan for Digital Participation. London: Department for Business, Innovation and Skills, 2010

[7] B. Lam, B., Y. K. Chan, J. Whittle, J. Binner, L. Garton, and K. Frankova, Voice Your View: An Inclusive Approach to Civic Engagement. Proceedings Include 2011. 2011.

[8] W. Simm, M. Ferrario, S. Piao, J. Whittle, P. Ray son. Classification of Short Text Comments by Sentiment and Actionability. Proceedings IEEE SocialCom 2010. Minneapolis, USA 2010. 